\title{
Lexicographic Product of Standard Graphs Using Claw Decompositions
}

\author{
${ }^{1}$ C.Sujatha and ${ }^{2}$ A.Manickam \\ ${ }^{1}$ Principal, Professor of Mathematics, Marudu Pandiyar College, Vallam Post, Thanjavur-613 403, \\ Tamilnadu, India. \\ Email id: sujatha2276@gmail.com \\ ${ }^{2}$ Assistant Prof of Mathematics, Marudu Pandiyar College, Vallam Post, Thanjavur-613 403, Tamilnadu, India. \\ Email id: manickammaths2011@gmail.com
}

\begin{abstract}
In this paper, we shall discuss necessary and sufficient condition for the decomposition of Cartesian products of standard graphs into claws. Also, we give a sufficient condition for the claw decomposition of Lexicographic product of standard graphs.
\end{abstract}

Keywords- Claw decomposition, Cartesian product, Lexicographic product.

\section{INTRODUCTION}

Let $G=\{V, E\}$ be a simple undirected graph without loops or multiple edges. A path on $\mathrm{n}$ vertices is denoted by $p_{n}$,cycle on $\mathrm{n}$-vertices is denoted by $c_{n}$ and complete graph on $\mathrm{n}$ vertices is denote by $k_{n}$. A decomposition of a graph $G$ is a family of Edgedisjoint subgraphs $\left\{G_{1}, G_{2}, G_{3}, G_{4}, \ldots . G_{k}\right\}$ such that $E(G)=E\left(G_{1}\right) U E\left(G_{2}\right) \ldots \ldots U E\left(G_{k}\right)$.If each $G_{i}$ is isomorphic to $\mathrm{H}$ for some subgraph $\mathrm{H}$ of $\mathrm{G}$,then the decomposition is called a H-decomposition of G. If $\mathrm{H}$ has at least three edges, then the problem of deciding if a Graph $\mathrm{G}$ has a H-decomposition is NPComplete[2].A star with three edges is a called a claw. A complete bipartite graph with partite sets $V_{1}$ and $V_{2}$, where $\left|V_{1}\right|=r$ and $\left|v_{2}\right|=S$, is denoted by $K_{r, s}$. The Graph $K_{1, r}$ is called star and is denoted by $S_{r}$. The vertex of degree $\mathrm{r}$ in the star $S_{r}$ is called the central vertex of the star.The complement of a graph $G$ is denoted by $\overleftarrow{G} . K_{G}$ denotes the union of $\mathrm{k}$ copies of G.The join $G+H$ of two graphs $\mathrm{G}$ and $\mathrm{H}$ consists of $G U H$ and all edges joining each vertex of $\mathrm{G}$ to all the vertices of H.Terms not defined here are used in the sense of [4].

If $\mathrm{h}$ has at least three edges,then the problem of deciding if a Graph $G$ has a $\mathrm{H}$ decomposition is NP-Complete[1,2]..

In 1975, Sumiyasu, yamamoto etal.., gave necessary and sufficient condition for the $S_{k}$ decomposition of complete graphs and complete bipartite graphs. In 1996, C.Lin and T.W Shyu[4]presented a necessary and sufficient condition for decompositions $K_{n}$ into stars

$$
S_{k_{1}}, S_{k_{2}} \ldots \ldots . S_{k_{t}}
$$

In 2004,H.L.Fu et al .,[3]

decomposed a complete graph into Cartesian product of two complex graphs $K_{r}, K_{t}$.

In 2012,Darry E.Bryant et al[1] gave necessary and sufficient condition for the existence of
$\mathrm{K}$-star factorizations of any power $K_{q}{ }^{s}$, where $\mathrm{q}$ is prime and the products

$$
C_{r_{1}} X C_{r_{2}} X C_{r_{3}} \ldots C_{r_{k}} \text { of k cycles of arbitrary }
$$

length.

In 2013 Tay-Woei shyu[5] gave necessary and sufficient condition for the decomposition of complete graph into $\mathrm{C}_{1}$ 's and $\mathrm{S}_{\mathrm{k}}$ 's.

In this paper, we give necessary and sufficient condition for decomposition of Cartesian product of standard graphs into claws. Also we give a sufficient condition for the claw-decomposition of lexicographic product of standard Graphs.

\section{PRELIMINARIES}

In this section,We collect ceratin lemma's and results which are used in the subsequent sections. These are the building blocks in the construction of the main theorems.

Definition 2.1

The corona of two graphs $G$ and $\mathrm{H}$,is the graph $\mathrm{GoH}$ formed from one copy of $\mathrm{G}$ and $|V(G)|$ copies of $H$ where the $i^{\text {th }}$ vertex of $G$ is adjacent to every vertex in the $i^{\text {th }}$ copy of $\mathrm{H}$.

\section{Definition 2.2}

The Cartesian product of two Graphs $\mathrm{g}$ and $\mathrm{H}$ is a graph, denoted by

$\mathrm{G} \times \mathrm{H}$, whose vertex set is $\mathrm{V}(\mathrm{G}) \mathrm{xV}(\mathrm{H})$. Two vertices (g.h) and $\left(\mathrm{g}^{1}, \mathrm{~h}^{1}\right)$ are adjacent precisely if $\mathrm{g}=\mathrm{g}^{1}$ and $\mathrm{h} \ddot{h} \in \mathrm{E}(\mathrm{H})$ or $\mathrm{g} \ddot{g} \in \mathrm{E}(\mathrm{G})$ and $\mathrm{h}=\mathrm{h}^{1}$.

Thus $\mathrm{V}(\mathrm{GxH})=\{(\mathrm{g} \cdot \mathrm{h}) / \mathrm{g} \in \mathrm{V}(\mathrm{G})$ and $\mathrm{h} \in$ $\mathrm{V}(\mathrm{H})\}$

$$
\left.\operatorname{gg}^{1} \in E(G) \text { and } h=h^{1}\right\}
$$

\section{Theorem 2.3}

A complete Graph , $\mathrm{k}_{1}$ with $l$ pairs and $(l / 2)$ lines can be decomposed into a union of line $\operatorname{disjoint}(l / 2) / c$ claws $\mathrm{K}_{1, \mathrm{c}}$ with $l$ lines each $\Leftrightarrow$ 


\section{Available online at www.ijrat.org}

\begin{abstract}
(i) $(l / c)$ is an integral multiple of $\mathrm{c}$ and
(ii) $l \geq 2 c$.
\end{abstract}

\section{Theorem 2.4}

A complete bigraph $K_{m, n}$ with $\mathrm{m}$ and $\mathrm{n}$ points and $\mathrm{mn}$ lines each the decomposed into union of $\mathrm{mn} / \mathrm{c}$ line disjoint $(l / 2) / c$ claws $\mathrm{k}_{1}, \mathrm{c}$ with $\mathrm{c}$ lines each $\Leftrightarrow$ if $\mathrm{m}$ and $\mathrm{n}$ satisfy one of the following three conditions. (i) $\mathrm{n}=0(\bmod \mathrm{c})$ when $\mathrm{m}<\mathrm{c}$

(ii) $\mathrm{m}=0(\bmod \mathrm{c})$ when $\mathrm{n}<\mathrm{c}$

(iii) $\mathrm{mn}=0(\bmod \mathrm{c})$ when $\mathrm{m} \geq \mathrm{c}$ and $\mathrm{n} \geq \mathrm{c}$

\section{Theorem 2.5}

all n.

The Graph $\mathrm{C}_{\mathrm{n}} \mathrm{o} \overleftarrow{k_{2}}$ is claw decomposable for

Proof:

Let $\mathrm{V}\left(\mathrm{C}_{\mathrm{n}}\right)=\left\{\mathrm{V}_{1}, \mathrm{~V}_{2}, \ldots . \mathrm{V}_{\mathrm{n}}\right\}$ And let $\mathrm{u}_{\mathrm{i}}$ and $\mathrm{w}_{\mathrm{i}}$ be the pendant vertices at $\mathrm{V}_{\mathrm{i}}$. then $<\left\{u_{i}, w_{i}, v_{i}, v_{i+1}\right\} \cong k_{1,3}$ for all $1 \leq i \leq n-1$ and $<\left\{u_{n}, w_{n}, v_{n}, v_{1}\right\} \cong k_{1,3}$

Thus $\mathrm{E}\left(\mathrm{Cn} 0 \overline{k_{2}}\right)=\mathrm{E}\left(\mathrm{k}_{1}, 3\right) \mathrm{U} \ldots \mathrm{U} \mathrm{E}\left(\mathrm{K}_{1,3}\right)$.

Hence $\mathrm{Cn} 0 \overline{k_{2}}$ is claw decomposable

Theorem 2.6

If $\mathrm{n}$ is even and $n \equiv 0(\bmod 3)$ then $\mathrm{k}_{2} \times \mathrm{C}_{\mathrm{n}}$ is claw decomposable.

Proof:

Let $\mathrm{V}\left(\mathrm{K}_{2}\right)=\left\{\mathrm{x}_{1}, \mathrm{x}_{2}\right\}$

And let $\mathrm{V}\left(\mathrm{C}_{\mathrm{n}}\right)=\left\{\mathrm{y}_{1}, \mathrm{y}_{2} \ldots \mathrm{y}_{\mathrm{n}}\right\}$ then $\mathrm{V}\left(\mathrm{k}_{2} \quad \mathrm{X}\right.$

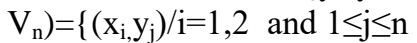

Rename $\left(\mathrm{x}_{1}, \mathrm{y}_{\mathrm{j}}\right)=\mathrm{v}_{\mathrm{j}}$ and $\left(\mathrm{x}_{2}, \mathrm{y}_{\mathrm{j}}\right)=\mathrm{u}_{\mathrm{j}} \forall 1 \leq \mathrm{j} \leq \mathrm{n}$..

Now

$\left\langle\left\{\mathrm{v}_{1}, \mathrm{v}_{2}, \mathrm{v}_{\mathrm{n}}, \mathrm{u}_{1}\right\}\right\rangle \cong K_{1,3}$

$\left\langle\left\{\mathrm{u}_{1}, \mathrm{u}_{\mathrm{n}-1}, \mathrm{u}_{\mathrm{n}}, \mathrm{v}_{\mathrm{n}}\right\}\right\rangle \cong K_{1,3}$

$\left\langle\left\{\mathrm{u}_{\mathrm{i}+1}, \mathrm{v}_{\mathrm{i}}, \mathrm{v}_{\mathrm{i}+1}, \mathrm{v}_{\mathrm{i}+2}\right\}>\cong K_{1,3} \forall \mathrm{i} \in\{2,4,6 \ldots \mathrm{n}-2\}\right.$

And

$<\left\{\mathrm{u}_{\mathrm{i}}, \mathrm{u}_{\mathrm{i}+1}, \mathrm{u}_{\mathrm{i}+2,}, \mathrm{u}_{\mathrm{i}+1}\right\}>\cong \forall \mathrm{i} \in\{1,3,5,7 \ldots \mathrm{n}-3\}$

Thus $\mathrm{E}\left(\mathrm{k}_{2} \quad \mathrm{X} \quad \mathrm{C}_{\mathrm{n}}\right)=\mathrm{E}\left(\mathrm{k}_{1,3}\right) \quad \mathrm{U} \ldots . \mathrm{U} \mathrm{E}\left(\mathrm{k}_{1}\right)$

Hence $\mathrm{k}_{2} \mathrm{X} \mathrm{C}_{\mathrm{n}}$ is claw decomposable.

\section{CLAW DECOMPOSITION OF CARTESIAN PRODUCT OF GRAPHS}

In this section we give necessary and sufficient condition for the decomposition of Cartesian product of some standard graphs into claws.

\section{Theorem 3.1}

If $\mathrm{G}_{1}$ and $\mathrm{G}_{2}$ are $\mathrm{H}$ decomposable then $\mathrm{G}_{1} \mathrm{X} \mathrm{G}_{2}$ is $\mathrm{H}$ decomposable.

\section{Proof:}

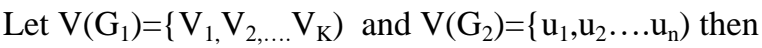
$\mathrm{V}\left(\mathrm{G}_{1} \quad \mathrm{XG}_{2}\right)=\left\{\left(\mathrm{v}_{\mathrm{i},} \mathrm{u}_{\mathrm{j} j}\right) 1 \leq \mathrm{i} \leq \mathrm{k}, 1 \leq \mathrm{j} \leq \mathrm{n}\right\}$

Rename $\left(\mathrm{v}_{\mathrm{i}}, \mathrm{u}_{\mathrm{j}}\right)=\mathrm{v}_{\mathrm{ij}} ; 1 \leq \mathrm{i} \leq \mathrm{k}, 1 \leq \mathrm{j} \leq \mathrm{n}$

Now

$\left\langle\left\{\mathrm{v}_{1, \mathrm{j}}, \mathrm{v}_{2, \mathrm{j}}, \ldots \mathrm{v}_{\mathrm{k}, \mathrm{j}}\right\}\right\rangle \cong \mathrm{G}_{1} \forall 1 \leq \mathrm{j} \leq \mathrm{n}$

$\left\langle\left\{\mathrm{u}_{\mathrm{i}, 1}, \mathrm{u}_{\mathrm{i}, 2}, \ldots \mathrm{u}_{\mathrm{i}, \mathrm{n}}\right\}\right\rangle \cong \mathrm{G}_{2} \forall 1 \leq \mathrm{i} \leq \mathrm{k}$

Thus $\mathrm{E}\left(\mathrm{G}_{1 \mathrm{X}} \mathrm{G}_{2}\right)=\mathrm{E}\left(\mathrm{G}_{1}\right) \mathrm{U} \ldots . . \mathrm{U} \mathrm{E}\left(\mathrm{G}_{1}\right) \mathrm{U} \mathrm{E}\left(\mathrm{G}_{2}\right) \mathrm{U} \ldots . \mathrm{U}$ $\mathrm{E}\left(\mathrm{G}_{2}\right)$
Since $\mathrm{G}_{1}$ and $\mathrm{G}_{2}$ is $\mathrm{H}$ decomposable

Corollary 3.2

If $\mathrm{m}, \mathrm{n} \equiv 0(\bmod 3)$ then $\mathrm{k}_{1, \mathrm{~m}} \mathrm{X} \mathrm{k}_{1, \mathrm{n}}$ is claw decomposable.

Corollary 3.3

If $\mathrm{m} \equiv 0(\bmod 3)$ and $\mathrm{n} \neq 2(\bmod 3)$ then

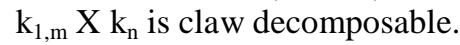

Proof:

Corollary 3.4

It follows the theorem 2.3. and 3.1

If $\mathrm{rs} \equiv 0(\bmod 3)$ and claw $\mathrm{n} \equiv 2(\bmod 3)$

then $\mathrm{k}_{\mathrm{r}, \mathrm{s}} \mathrm{X} \mathrm{k}_{\mathrm{n}}$ is claw decomposable.

Proof:

It follows the theorem 2.3,2.4and 3.1

Corollary 3.5

If $\mathrm{rs} \equiv 0(\bmod 3)$ and claw $\mathrm{n} \equiv 0(\bmod 3)$

then $\mathrm{k}_{\mathrm{r}, \mathrm{s}} \mathrm{X} \mathrm{k}_{1, \mathrm{n}}$ is $\mathrm{k}_{1,3}$ decomposable.

Proof:

It follows from theorem 2.4 and 3.1

\section{CLAW DECOMPOSITION OF LEXICOGRAPHIC PRODUCT OF GRAPHS}

In this section, we give sufficient condition for the lexicographic product of any Graphs $G$ with $\overline{k_{n}}, \mathrm{k}_{\mathrm{n}}, \mathrm{k}_{\mathrm{m}, \mathrm{n}}$ and $\mathrm{k}_{2} \times \mathrm{k}_{\mathrm{n}}$ to be claw decomposable.

Definition 4.1

The lexicographic product of two Graphs $\mathrm{G}$ and $\mathrm{H}$ is a Graph denoted by $\mathrm{G} * \mathrm{H}$, whose vertex set is $\mathrm{V}(\mathrm{G}) \mathrm{x}$ $\mathrm{V}(\mathrm{H})$.Two vertices $(\mathrm{g}, \mathrm{h})$ and $(\dot{g}, \dot{h})$ are adjacent precisely if $g \dot{g} \in \mathrm{E}(\mathrm{G})$,or $\mathrm{g}=\dot{g}$ and $\mathrm{h} \dot{h} \in \mathrm{E}(\mathrm{H})$.

The other way of viewing $\mathrm{G} * \mathrm{H}$ is by replacing each vertex in $\mathrm{G}$ by a copy of $\mathrm{H}$ and two vertices in $\mathrm{G}$ are adjacent if and only if if there exists a complete bipartite sub graph with the corresponding vertices of $\mathrm{H}$ as partite sets in $\mathrm{G}^{*} \mathrm{H}$.

\section{Theorem 4.2}

Let $\mathrm{G}$ be any non-trivial Graph.It $\mathrm{n} \equiv$ $0(\bmod 3)$,then $\mathrm{G}^{*} \overline{k_{n}}$ is claw decomposable.

\section{Proof:}

Assume that $\mathrm{n} \equiv 0(\bmod 3)$

Let $\mathrm{V}(\mathrm{G})=\left\{\mathrm{v}_{1}, \mathrm{v}_{2} \ldots . \mathrm{v}_{\mathrm{k}}\right\}$

And $\mathrm{V}\left(\overline{k_{n}}\right)=\left\{\mathrm{u}_{1}, \mathrm{u}_{2} \ldots \mathrm{u}_{\mathrm{n}}\right\}$

Then $\mathrm{V}\left(\mathrm{G} * \overline{k_{n}}\right)=\left\{\left(\mathrm{v}_{\mathrm{i}}, \mathrm{u}_{\mathrm{j}}\right) / 1 \leq \mathrm{i} \leq \mathrm{k}, 1 \leq \mathrm{j} \leq \mathrm{n}\right\}$

Rename

$\left(\mathrm{V}_{\mathrm{i}, \mathrm{u}_{\mathrm{j}}}\right)=\mathrm{V}_{\mathrm{ij}} ; 1 \leq \mathrm{i} \leq \mathrm{k}, 1 \leq \mathrm{j} \leq \mathrm{n}$

Now for each $\mathrm{v}_{\mathrm{i}, \mathrm{v}_{\mathrm{j}} \in} \in$

$\mathrm{E}(\mathrm{G})<\left\{\mathrm{v}_{1, \mathrm{i}, \mathrm{V}} \mathrm{v}_{2, \mathrm{i} \ldots . .} \mathrm{v}_{\left.\mathrm{n} . \mathrm{i}, \mathrm{V} 1, \mathrm{j}, \mathrm{v}_{2, \mathrm{j}} \ldots . . \mathrm{Vn}, \mathrm{j}\right\}} \cong \mathrm{k}_{\mathrm{n}, \mathrm{n}}\right.$

Thus $\mathrm{E}\left(\mathrm{G} * \overline{k_{n}}\right)=\mathrm{E}\left(\mathrm{k}_{\mathrm{n}, \mathrm{n}}\right) \mathrm{U} \ldots . \mathrm{UE}\left(\mathrm{k}_{\mathrm{n}, \mathrm{n}}\right)$

Since $\mathrm{n} \equiv 0(\bmod 3)$, by thorem $2.4 K_{\mathrm{n}, \mathrm{n}}$ is claw decomposable.

Hence $\mathrm{G} * \overline{k_{n}}$ is claw decomposable

Theorem 4.3

Let $\mathrm{G}$ be any non-trival graph.If $\mathrm{n}>3$ and $\mathrm{n} \equiv 0(\bmod 3)$, then $\mathrm{G}^{*} \mathrm{~K}_{\mathrm{n}}$ is claw decomposable.

Proof: 
Assume that $\mathrm{n}>3$ and $\mathrm{n} \equiv 0 \bmod 3$

Let $V(G)=\left\{v_{1}, v_{2}, \ldots . v_{k}\right)$

And $\mathrm{V}\left(\mathrm{K}_{\mathrm{n}}\right)=\left\{\mathrm{u}_{1}, \mathrm{u}_{2, \ldots}, \mathrm{u}_{\mathrm{n}}\right)$

Then $\left.\mathrm{V}\left(\mathrm{G}^{*} \mathrm{~K}_{\mathrm{n}}\right)=\left(\mathrm{v}_{\mathrm{i}}, \mathrm{u}_{\mathrm{j}}\right) / 1 \leq \mathrm{i} \leq \mathrm{k}, 1 \leq \mathrm{j} \leq \mathrm{n}\right\}$

Rename

$\left(\mathrm{V}_{\mathrm{i},} \mathrm{u}_{\mathrm{j}}\right)=\mathrm{V}_{\mathrm{ij}} ; 1 \leq \mathrm{i} \leq \mathrm{k}, 1 \leq \mathrm{j} \leq \mathrm{n}$

Now

$<\left\{\mathrm{v}_{1}, \mathrm{v}_{2}, \ldots . \mathrm{v}_{\mathrm{n}}\right\}>\cong \mathrm{k}_{\mathrm{n}} \forall 1 \leq \mathrm{i} \leq \mathrm{k}$,

Also for each $v_{\mathrm{i},} \mathrm{v}_{\mathrm{j}} \in \mathrm{E}(\mathrm{G})$

$\left\langle\left\{\mathrm{v}_{1 \mathrm{i}}, \mathrm{v}_{2 \mathrm{i}}, \ldots \mathrm{v}_{\mathrm{ni}}, \mathrm{v}_{1 \mathrm{j}}, \mathrm{v}_{2 \mathrm{j} \ldots} \ldots \mathrm{v}_{\mathrm{ng}}\right\rangle\right.$

$\mathrm{E}\left(<\left\{\mathrm{V}_{1 \mathrm{i}}, \mathrm{V}_{2 \mathrm{i}} \ldots \ldots . . . \mathrm{V}_{\mathrm{ni}}>\right)\right.$

$\mathrm{E}\left(<\left\{\mathrm{V}_{1 \mathrm{j}}, \mathrm{V}_{2 \mathrm{j} \ldots \ldots . . .} \mathrm{V}_{\mathrm{nj}}\right\rangle\right) \cong \mathrm{k}_{\mathrm{n}, \mathrm{n}}$

Thus $\mathrm{E}\left(\mathrm{G} * \mathrm{~K}_{\mathrm{n}}\right)=\mathrm{E}\left(\mathrm{K}_{\mathrm{n}}\right) \mathrm{U} \ldots . \mathrm{U} \mathrm{E}\left(\mathrm{K}_{\mathrm{n}}\right) \mathrm{U} \mathrm{E}\left(\mathrm{K}_{\mathrm{n}, \mathrm{n}}\right)$

Since $\mathrm{n} \equiv 0 \bmod (3)$ by them 2.3 and 2.4 and $\mathrm{k}_{\mathrm{n}, \mathrm{n}}$ are

claw decomposable .

Hence $\mathrm{G} * \mathrm{~K}_{\mathrm{n}}$ is claw decomposable.

\section{CONCLUSION}

In this paper, we shall discuss about claw decomposition of Product graphs. We give necessary and sufficient condition for the decomposition of Cartesian product stdand ard and ordinary graphs into claws. Also we give a sufficient condition for the claw decomposition of lexicographic product of standard and ordinary graphs has been clearly understood and discussed in this research article.

\section{REFERENCES}

[1] Darry E.Bryant,Saad EL.Zanati and charless vanden Eyden (2001). "Star factorization of graph products”Journal of Graph theory 36 PP 59-66.

[2] H.L.Fu,F.K.Hwang.MJimboYMutoh,C.L.shiue(2 004). "Decomposition and complex graphs into $\mathrm{K}_{\mathrm{r}} \mathrm{X} \mathrm{K}_{\mathrm{c}}$ 's'”Journal of Statistical Planning and Interference119. PP 225-236.

[3] [C.Lin and T.W.Shyu (1996)."A necessary and sufficient condition for the star decomposition of complete graphs"Journal of Graph theory. 23:361-364.

[4] P.Chitra devi and J.Paulraj Joesph (2014). "Claw decomposition of product graphs". International Journal of Mathematical Science.vol.13.Jan -June.

[5] Tay.Woei shyu. (2013). "Decomposition of complete graphs into cycles and stars "Graphs and combinotorics 29 pp:311-313. 